\title{
BUILDING A NUMERICAL MODEL OF THE FILTRATION FLOW IN THE ŻELAZNY MOST FLOTATION TAILINGS DISPOSAL LAKE
}

\author{
TOMASZ STRZELECKI, ŁUKASZ MANIECKI \\ Wrocław University of Technology, Institute of Geotechnics and Hydrotechnics, \\ e-mail: tomasz.strzelecki@pwr.edu.pl
}

MONIKA BARTLEWSKA-URBAN

Wrocław University of Technology, Institute of Mining, e-mail: monika.bartlewska@pwr.edu.pl

\begin{abstract}
The paper presents results of numerical computations of the filtration flow of liquid contaminated wastes through the Żelazny Most flotation tailings disposal lake. Unlike the preceding papers [5]-[7], it takes the geological structure of the subsoil into account. A three-dimensional numerical model of the lake was created for computing purposes. Data on some of the effective model parameters were acquired from laboratory tests of the material taken from the lake site. The other data were taken from the literature for media of similar properties. The results of the computations carried out using the model can be a basis for future numerical analyses aimed at determining the consolidation of the flotation tailings disposal lake and its subsoil, and the stability of the lake.
\end{abstract}

Key words: filtration flow, three-dimensional numerical model, flotation wastes, tailings disposal lake

\section{INTRODUCTION}

Żelazny Most - the largest flotation tailings disposal lake and one of the largest hydro-engineering structures in the world - plays a major role in the operations of the KGHM Polska Miedź S.A. mines and in their environmental impact assessment. The use of mine wastes for erecting the lake embankment crown is critical for the stability of this hydro-engineering structure. Żelazny Most plays a key role in the water and sludge management of the three Ore Processing Plants which concentrate the copper ore output through flotation. Undoubtedly, this is a unique project. The facility has a circumference of about $15 \mathrm{~km}$ and the KGHM mines rate of production is such that its capacity is continuously being increased by adding further terraces to the embankment surrounding the lake. The most important elements of this facility, i.e., water intakes and discharges and dams, are under constant geotechnical monitoring. The data from measurements are systematically analyzed and a decision on the next raising of the crown is made after a thorough analysis carried out by a team of experts. Considering the above, it seems reasonable to create increasingly accurate models of the behaviour of this structure under the influence of various boundary conditions.

This paper provides a significant complement - in the form of the geological structure of the subsoil - to the existing three-dimensional model of the flotation tailings disposal lake. For the purpose of this study a survey of the available source materials on the lake and its infrastructure and geological structure was carried out. As a result, a spatial geological model of the lake area was created which served as the basis for building a spatial model of the filtration flow. The numerical computations were performed using the finite element method and professional IT tools.

\section{LOCATION OF FACILITY AND ITS GEOMETRIC PARAMETERS}

The Żelazny Most flotation tailings disposal lake is located between Rudna and Żelazny Most at the border between the Lubin District and the Polkowice District in the Lower Silesian Province. The facility occupies land belonging to three municipalities: Rudna, Polkowice and Grębocice. The locatation of the facility is shown in the satellite photograph in Fig. 2. 
The facility belongs to KGHM Polska Miedź S.A. which deposits in it tailings from the copper ore enrichment process conducted using the flotation method. The tailings are deposited in the form of liquid sludge in the amount of 20-60 M tons per annum. The lake's area above the terrain level amounts to $13.94 \mathrm{~km}^{2}$. The lake has a radius of $2.1-2.7 \mathrm{~km}$ and a circumference of $14.3 \mathrm{~km}$. The lake's height above the terrain level ranges from 35 to $55 \mathrm{~m}$. The lake's volume amounts to about $500 \mathrm{M} \mathrm{m}^{3}$ and its maximum possible capacity amounts to about 1.1 billion $\mathrm{m}^{3}$. The view of the lake is shown in Fig. 1.

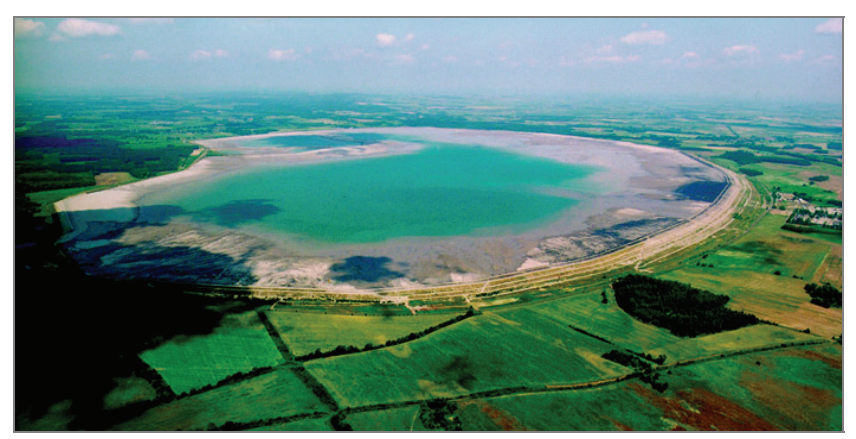

Fig. 1. View of Żelazny Most flotation tailings disposal lake

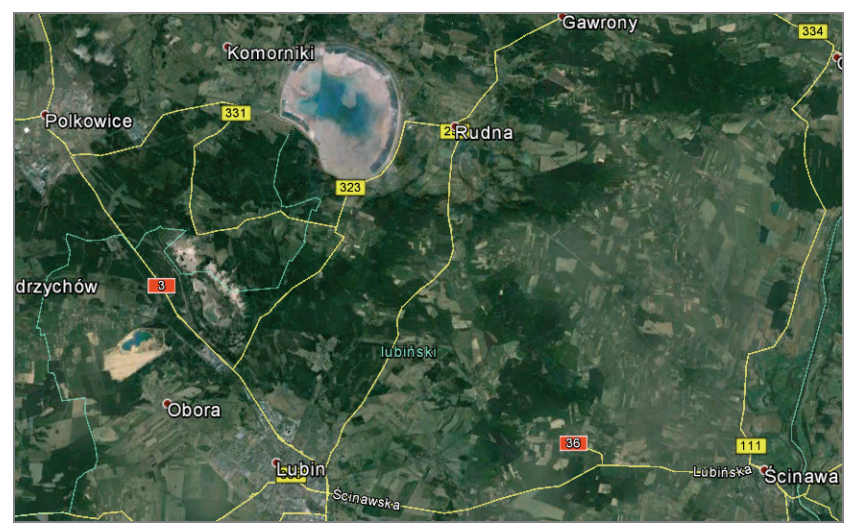

Fig. 2. Satellite photo image showing location of Żelazny Most lake

\section{DATA FOR NUMERICAL COMPUTATIONS OF FILTRATION FLOW}

The quality and accuracy of any computational analysis are limited by the range and reliability of the available input information. The starting point for building a numerical model of the filtration flow for the Żelazny Most flotation tailings disposal lake, including the subsoil, was an analysis of the geological structure and hydrogeological conditions of the subsoil.

\subsection{GEOLOGICAL STRUCTURE OF SUBSOIL}

The Żelazny Most flotation tailings disposal lake is located in the morphologic depression of the southeastern part of the Dałków Hills. The moreinal hills were formed as a result of the South Polish glaciation and the Mid-Polish glaciation. Formations of Quaternary and Tertiary loams constitute the lake's subsoil. The formations were subjected to numerous glaciotectonic deformations, the various forms of which are found in the different parts of the lake. The roof Tertiary formations were folded during the first glaciation while in the Oder stadial the glacier remodelled the end moraine, causing numerous overthrusts, heaves and disturbances of the deposits, extending to the depth of $150 \mathrm{~m}$ below the terrain level (Dyor [2]). The Quaternary is represented by Pleistocene deposits formed as boulder clays, sand-gravel water-glacial deposits and Holocene mud banks in the valleys of the Kalinówka River and the Lipówka River. The thickness of the Quaternary deposits ranges from a few to over 100 meters. The Tertiary formations are represented by mainly Pliocene loams of various thickness, often interfolded with a complex of Quaternary clays or sandgravel deposits. Locally separated from the basement and displaced loams occur in the form of plates and xenoliths within the fluvioglacial formations [2].

\subsection{HYDROGEOLOGICAL CONDITIONS}

As regards the hydrological conditions, two multiaquifer formations: the Quaternary formation and the Tertiary formation play a major role. The Quaternary water-bearing formations of variable thickness form irregular underground water reservoirs in the form of troughs, basins and lens. Larger spreads of unconfined aquifers deposited at a depth of 0-2 $\mathrm{m}$ below the terrain level are observed in the valleys of the watercourses. Among the folded Tertiary structures there are deposited aquifers isolated by loams and clays. They are characterized by a subartesian or artesian water table and a pressure extending a few meters above the terrain level (Czmiel, Markiewicz [1]). The natural water circulation conditions in the surroundings of the disposal lake have been disturbed as a result of the infiltration of water from the above-sludge lagoon. The pressures in the Quaternary aquiferous layers have increased as a result of hydraulic connections with the waters present in the flotation tailings disposal lake. The pressure in the deeper Tertiary aquifers is increasing (Dyor [2]). The infiltrating waters flow mainly through the first sand-gravel stratum. 


\subsubsection{DRAINAGE FACILITIES}

The drainage system of the Żelazny Most lake is complex, consisting of the following three main interacting components: perimeter drainage ditches, a horizontal drainage system under the dam together with ring drainage systems built into the lake, and vertical drainage in the form of dewatering wells.

Parameter drainage ditches are located at the toes of the dams under construction. The arrangement and denotations of the drainage ditches are shown in Fig. 3.

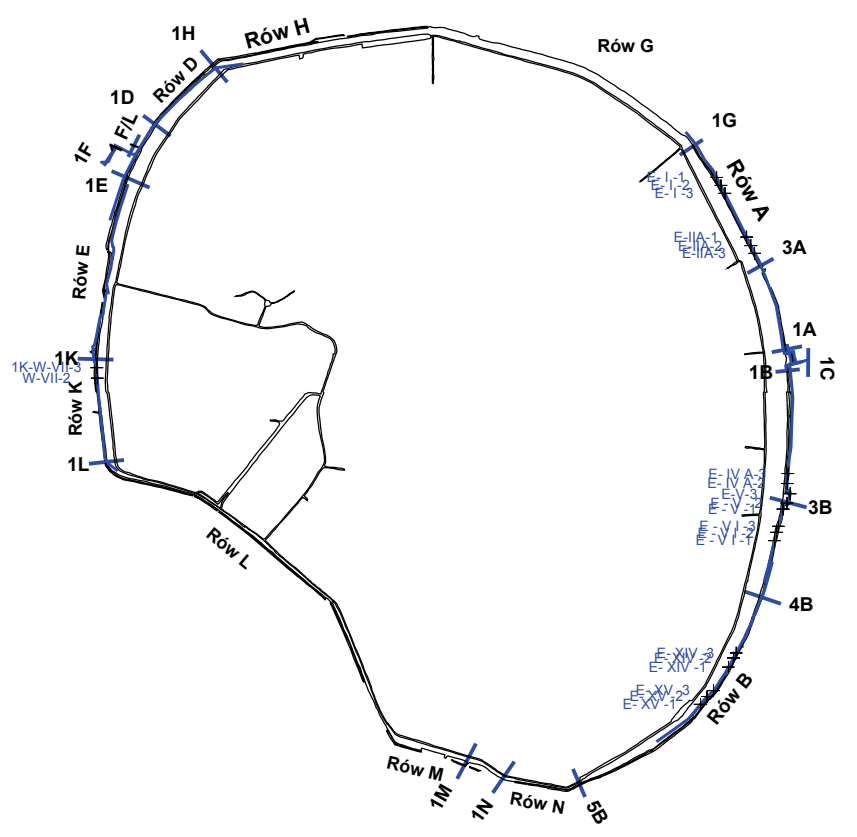

$1 \mathrm{~A}, \ldots, 5 \mathrm{~B}-$ stationary gauging sections E-I-1, ..., W-II-3 - drainage gauging sections

Fig. 3. Schematic showing arrangement of perimeter ditches and gauging sections

The horizontal drainage consists of the ring drainage, located deep in the massif of deposits, at a distance of about 100-150 m from the downstream slope of the lake, on two levels, and the drainage under the dam under construction. The horizontal drainage was made in the form of pipe drainage surrounding a complex layered filter encased with geo-textile.

The presented model also includes the filtration flow monitoring systems and data on the location (precise coordinates) of piezometers in the lake and in the surrounding area, made available by KGHM Polska Miedź S.A. - the Hydrotechnical Plant. The data from measurements carried out in 2007 were used to compare the results of the model numerical computations with the actual measured values.

\subsection{NUMERICAL MODEL OF TERRAIN}

In order to build a process model which would most accurately represent the actual conditions first the data on the geometry of the studied area had to be thoroughly analyzed. In the case of geological studies, the data include: the spatial mapping of the strata, the disturbances, the aquifers and the underground water levels. It should be noted that a simplified representation of the geology, in the form of a soil profile, predominates in engineering practice. But this makes only one- and two-dimensional simulations of the processes possible. Having a spatial representation of the geometry of an area one can perform three-dimensional analyses and numerical computations, and so more accurately approximate the real conditions. Thanks to this technique one can acquire the necessary geometrical data as well as present and compare the analytical results within the space of the investigated area. Particularly useful is the location of the free water table relative to the terrain level and the geological strata of the subsoil. Obviously, up-to-date data must be used in order to create an up-to-date model of the filtration flow. Since there were no such data the numerical model of the lake area created in 2008 by the BMT firm from Gdynia was used. The model includes the surface of the lake area, shown in Fig. 4, and the surface of the area before flotation tailings disposal, shown in Fig. 5, as well as geometrical data on the location of the perimeter ditches, the dewatering wells and the ring drainage within the lake.

The above model was an extended version of the DTM presented by Nowak et al. [5], which did not include the geological structure of the subsoil. Owing to this it was possible to compare the results yielded by the two models (the Nowak model and the numerical model needed to build a filtration model) and see the effect of the inclusion of the previously unavailable information about the geology of the terrain. The numerical model of the terrain was generated using a CAD software package by Bentley Systems (Bentley MicroStation V8i + Bentley InRoads Group V8.11).

The schematics of the surface of the lake area and the surrounding terrain, modified for the needs of the model, are shown below.

By combining the surface of the terrain around the lake (Fig. 5b) with the surface of the original terrain under the lake (Fig. 4b) the surface of the terrain shown in Fig. 5c was obtained and became the starting point for the model being generated. Using the geological cross-sections numerical models of the soles of the particular geological strata were created and ultimately a spatial geological model of the hydrotechnical lake with its subsoil was created. 


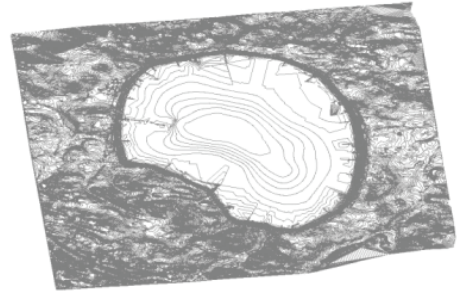

a)

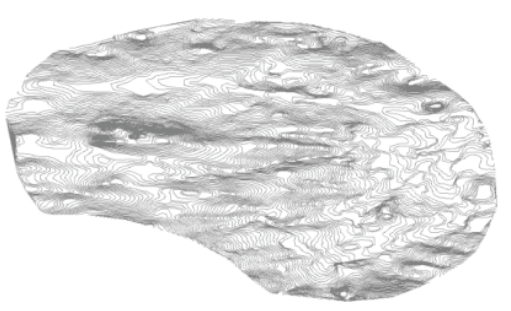

b)

Fig. 4. (a) Surface of terrain with flotation talings disposal lake, (b) surface of terrain under lake

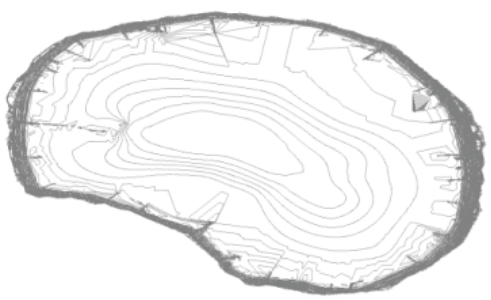

a)

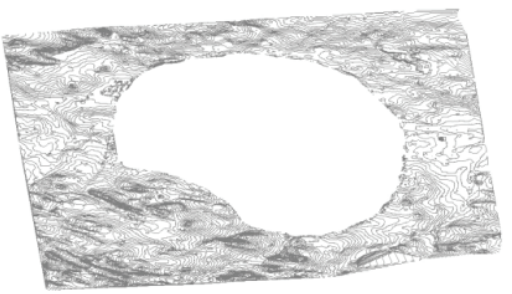

b)

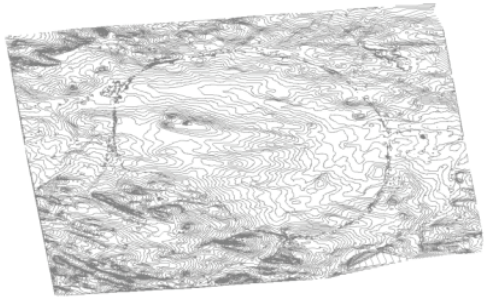

c)

Fig. 5. (a) Surface of lake area, (b) surface of original terrain without flotation tailings disposal lake, (c) surface of original terrain

\section{MATHEMATICAL MODEL OF FILTRATION FLOW}

The mathematical equations of the filtration process presented below are based on work [7], by Strzelecki et al. [7]. The model used for numerical computations is based on the following assumptions:

- a porous medium forms the structure of a solid body (a continuous medium) which has a regular network of interconnected filtration channels,

- closed pores, containing a liquid or a gas, are not present,

- the pores are filled with a liquid,

- the temperature is constant (an isothermal process),

- the skeleton of the soil medium does not exhibit non-dilatational strains,

- the porosity of the two-phase medium is a constant quantity.

According to [7], the solution of the non-steady flow problem comes down to the following secondorder differential equation:

$$
\operatorname{div}\left(\operatorname{grad}\left(k^{*} H\right)=a \frac{\partial H}{\partial t} .\right.
$$

The components of the seepage velocity vector are calculated in accordance with Darcy's law

$$
v_{i}=-\operatorname{grad}(H)
$$

where $H$ - the hydraulic head expressed by

$$
H=\frac{p}{\rho g}+z^{*} \delta_{i 3},
$$

$P$ - water pressure, $\rho$-water density, $a-$ a coefficient of compressibility of the aquiferous layer.

\section{GEOMETRY OF FACILITY AND BOUNDARY CONDITIONS OF PROBLEM}

The particular geological strata and the distinguished subareas of the hydrotechnical lake with stepwise variable hygrogeological parameters were transferred to Flex PDE v. 635. The geometry of the subsoil and the lake, with the generated finite elements, is shown in Fig. 6.

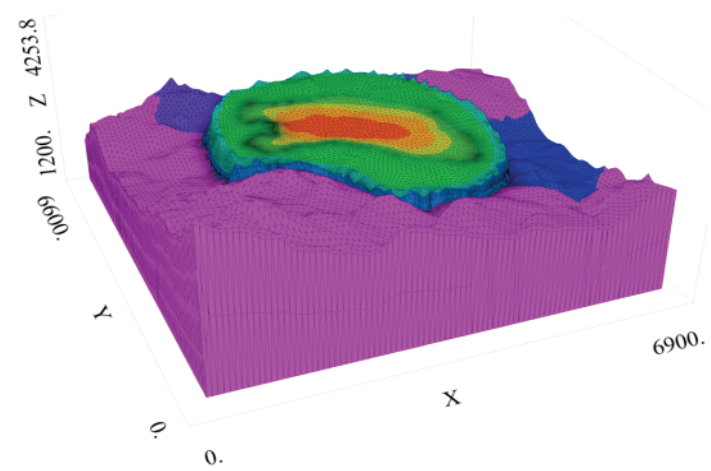

Fig. 6. Geometry of whole area with generated finite elements, shown in axonometric view 

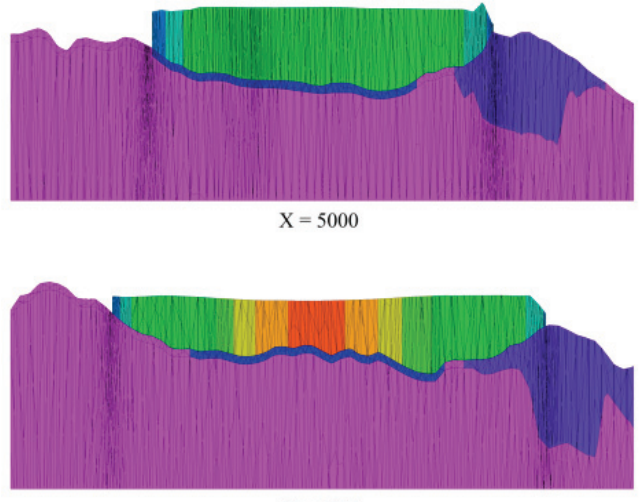

$X=4000$

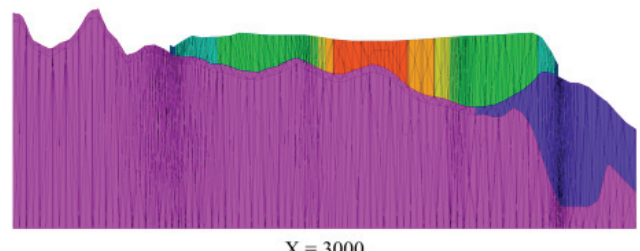

$X=3000$

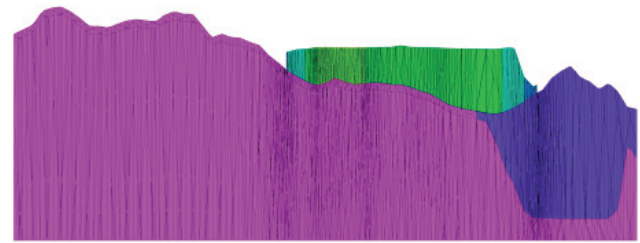

$X=2000$

Fig. 7. Model cross-sections in $y-z$ plane for $x=2000, x=3000$, $x=4000$ and $x=5000$, taking into account the kind of material

Figure 7 shows the generated cross-sections in the $y-z$ plane.

Owing to such a presentation of the cross sections the layout of the strata (differing in their hydrogeological parameters) in the lake and in the subsoil becomes visible. Figure 8 shows the division into regions within the hydrotechnical lake. The other regions apply solely to the subsoil.

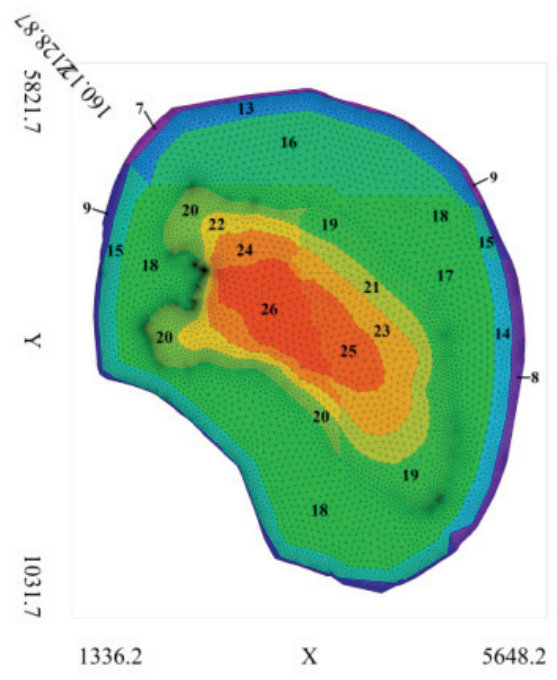

Fig. 8. Division into regions within hydrotechnical lake

The filtration coefficient values for the particular regions were adopted through model calibration, taking into account the distribution of filtration coeffi-

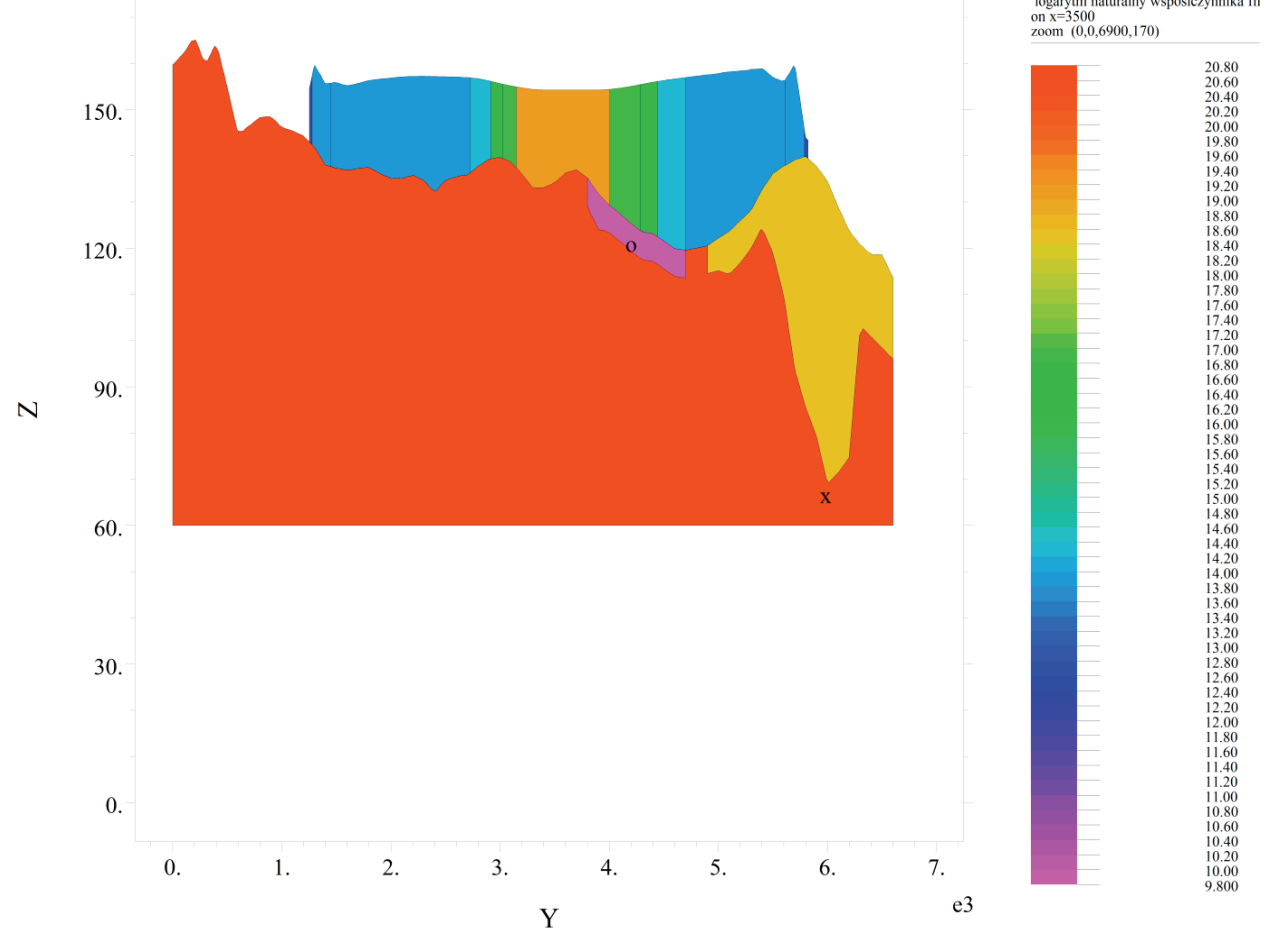

Fig. 9. Natural logarithm of filtration coefficient 
cient values in the lake depending on the size of the deposited flotation tailings fractions, proposed by Strzelecki et al. [7].

\subsection{PROBLEM BOUNDARY CONDITIONS}

In 3D models it is possible to define boundary conditions on the horizontal surfaces and vertical edges of the particular subareas. The surface area of the free water table was determined for the case when the free surface of underground water is in contact with the body of water at the top surface of the lake.

The following assumptions were made when determining the boundary conditions on the particular surfaces and edges:

- the lowest sole of a loam layer is impermeable,

- the condition of consistency of the size of $\mathrm{H}$ holds between the strata and the edges,

- at the outermost edges of the area the water level amounts to $1 \mathrm{~m}$ below the terrain level,

- the water level in horizontal drains and in a drainage ditch agrees with the height of the drains and the ditch,

- the water level in the place where a well operates is equal to the water level in the well.
The water level of $1 \mathrm{~m}$ below the subsoil level was assumed as the initial condition for the water table.

\section{RESULTS \\ OF NUMERICAL COMPUTATIONS OF FILTRATION}

Numerical computations were performed using FlexPDE Professional Version 5.0.7 3D (FlexPDE User Guide, 2000) under the assumptions: the minimum allowable error not greater than $0.5 \mathrm{~m}$, the minimum finite element mesh density -85 elements on the outer edge of the area, the allowable shape coefficient of the finite elements - 15 and the density of the vector field of water flow directions -100 . The maximum computing error amounted to $5.78 \cdot 10^{-4} \mathrm{~m}$. Figure $10 \mathrm{a}$ shows the vector field of water seepage velocity in the $x-y$ plane at elevation $z=90 \mathrm{~m}$. Figures $10 \mathrm{~b}$ and $10 \mathrm{c}$ show the vector field of water seepage velocity in the $x-z$ plane for cross sections $x$ and $y$.

Figures 11-13 show the free surface of the underground waters while Figs. 14 and 15 show its location relative to the terrain level and the lake surface.

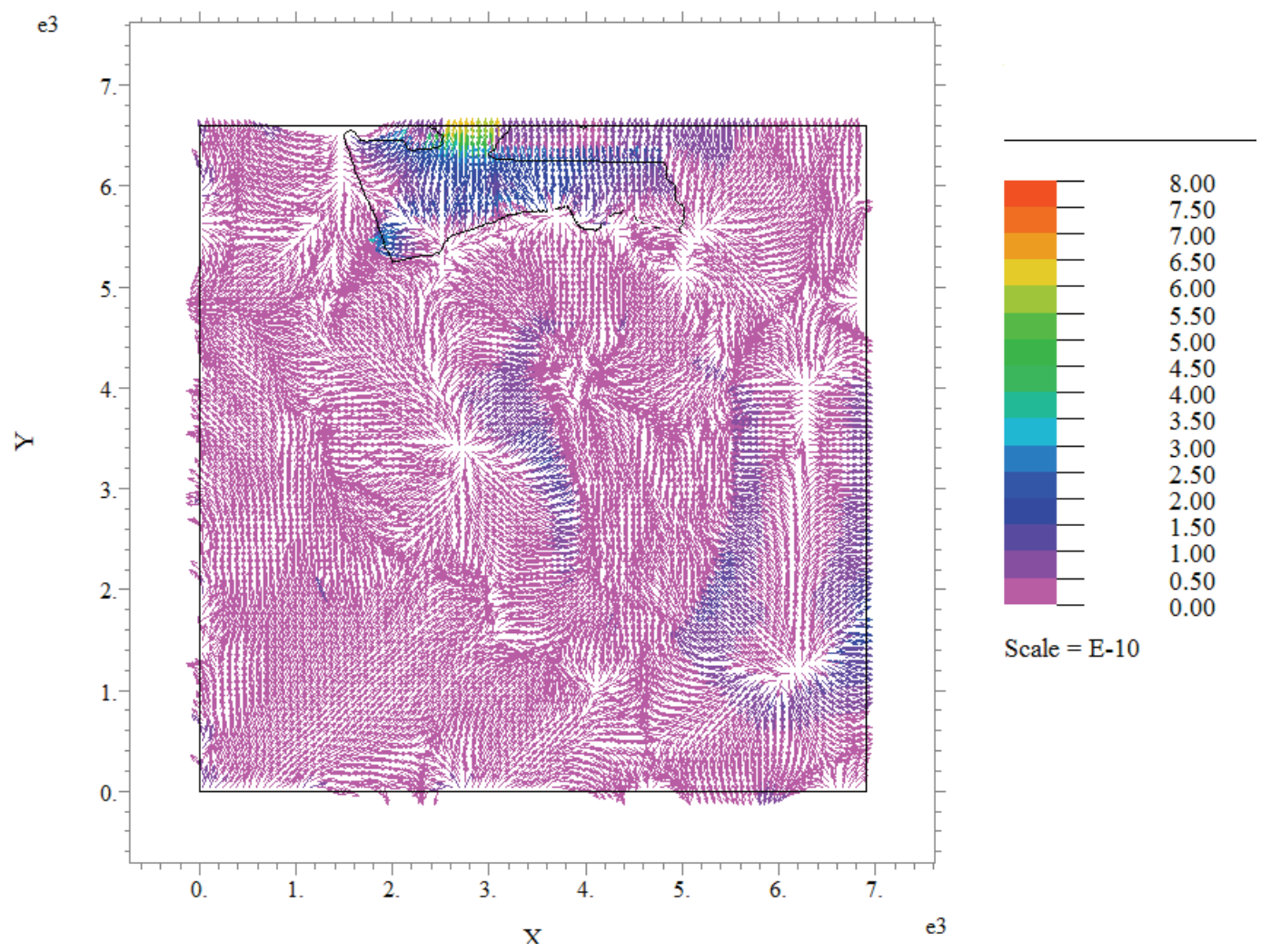

Fig. 10a. Vector field of water seepage velocity $[\mathrm{m} / \mathrm{s}]$ in plane $x-y$ at elevation $z=90$ 


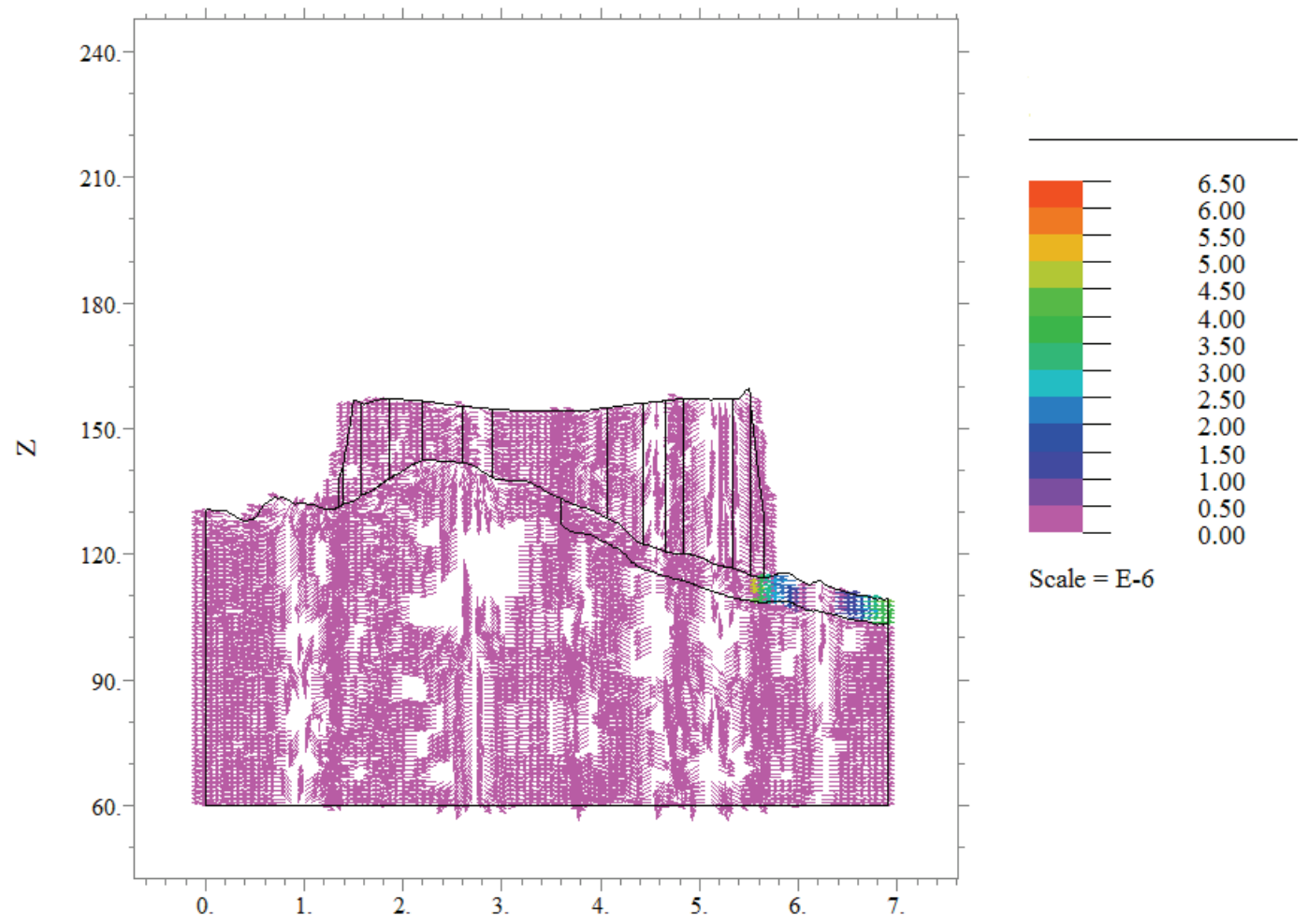

Fig. 10b. Vector field of water seepage velocity $[\mathrm{m} / \mathrm{s}]$ in plane $x-z$ in cross section $y=3500$

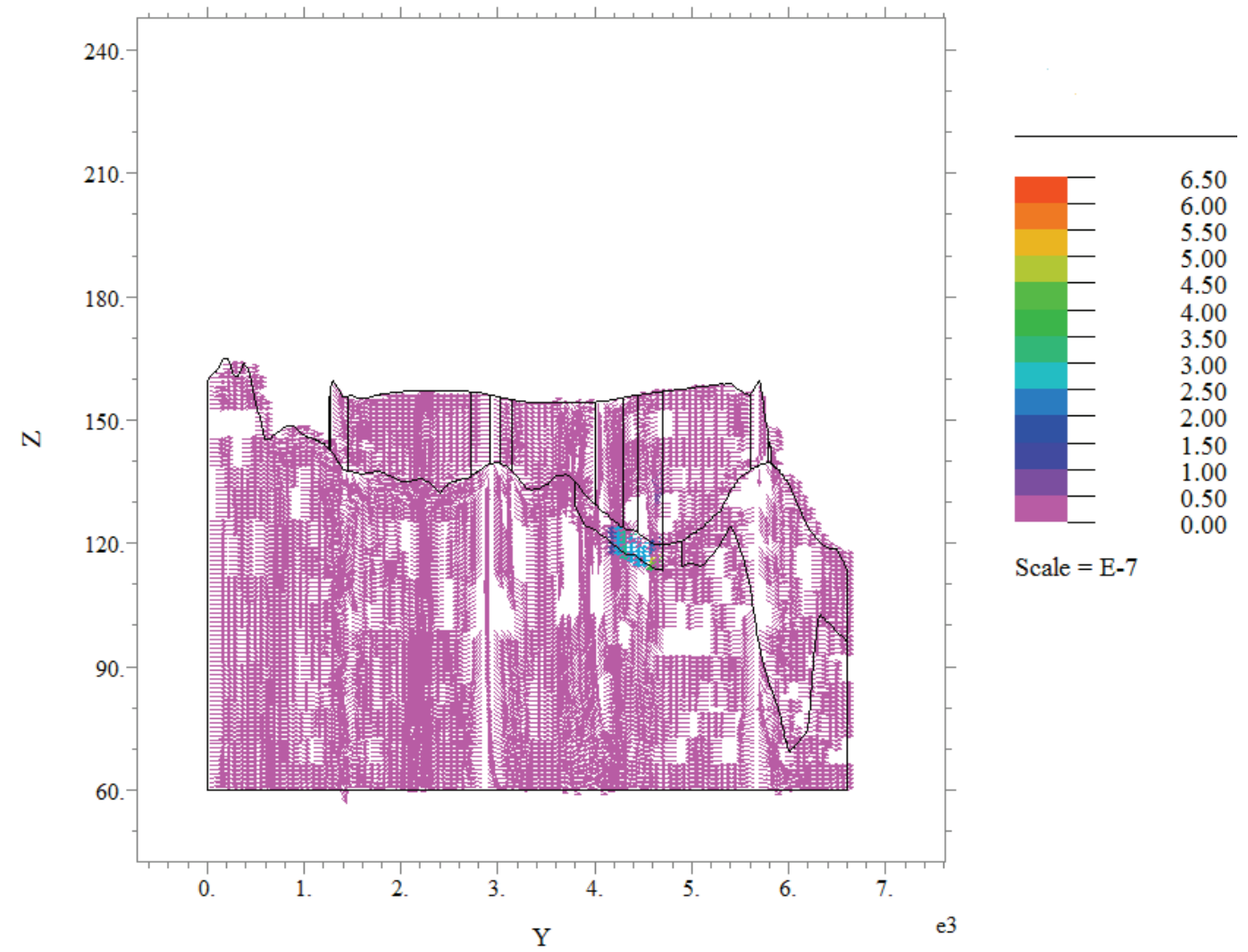

Fig. 10c. Vector field of water seepage velocity in plane $y-z$ in cross section $x=3500$ 


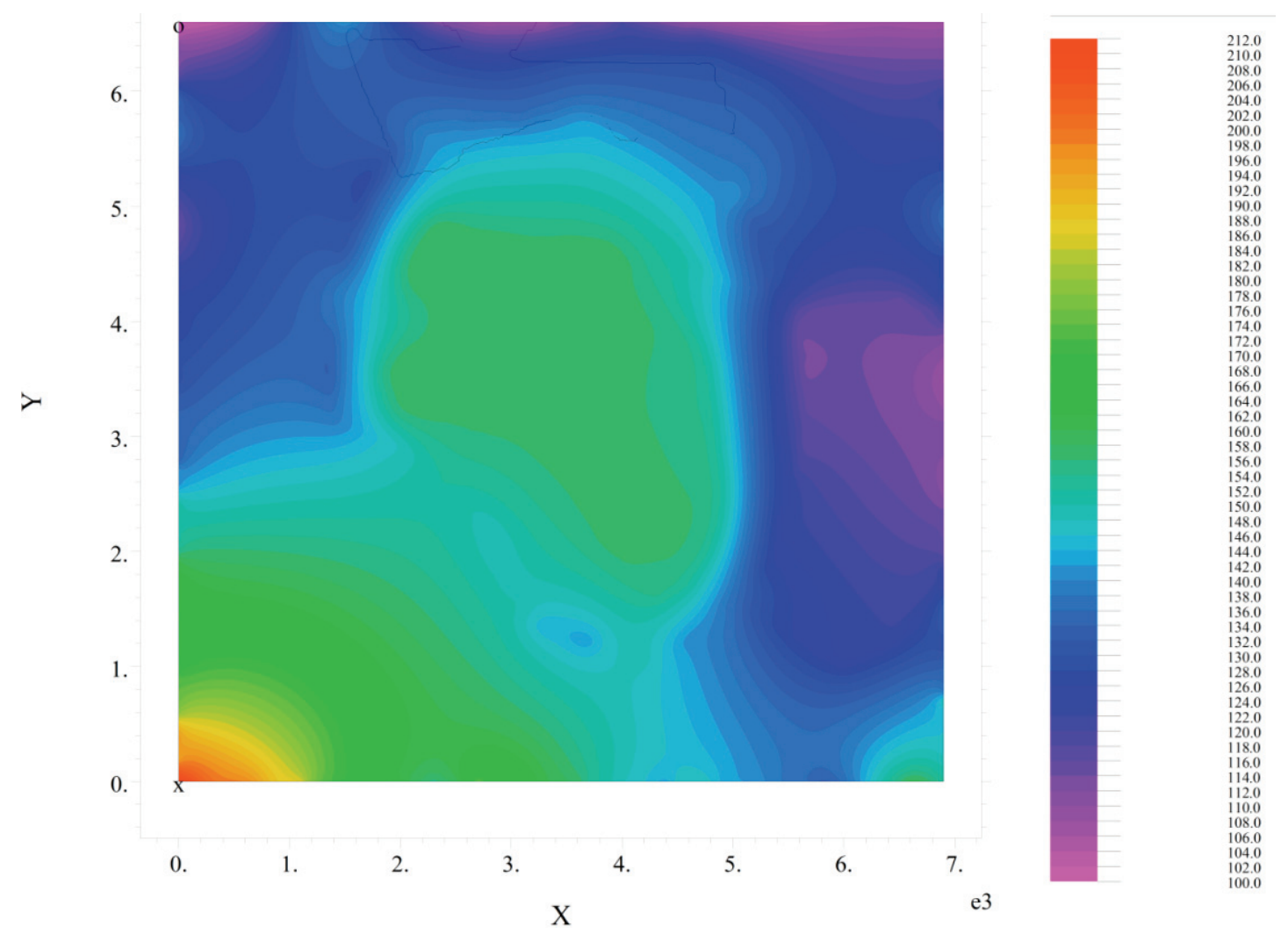

Fig. 11. Height of subterranean water table

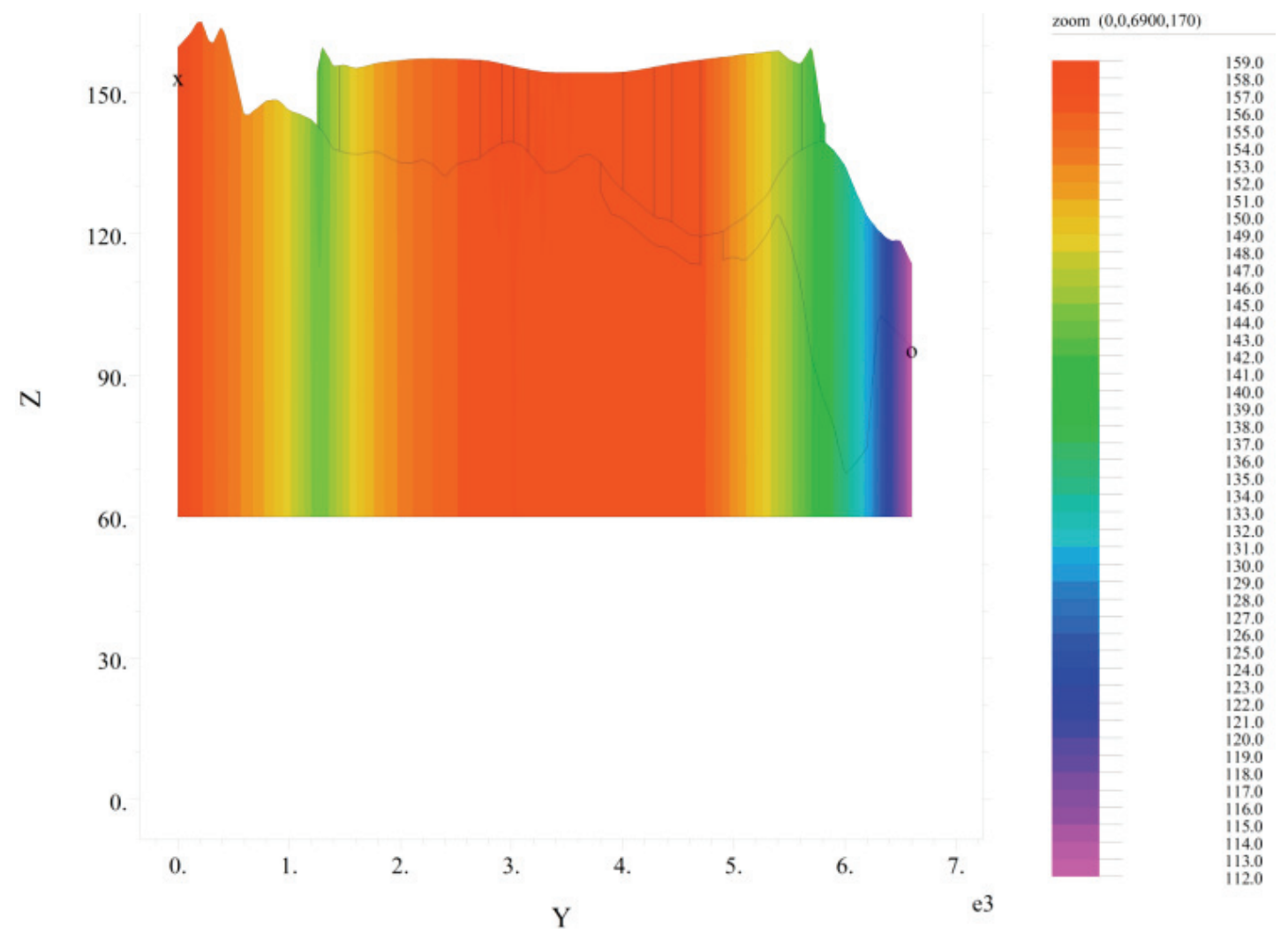

Fig. 12. Height of subterranean water table in cross section $x=3500$ 


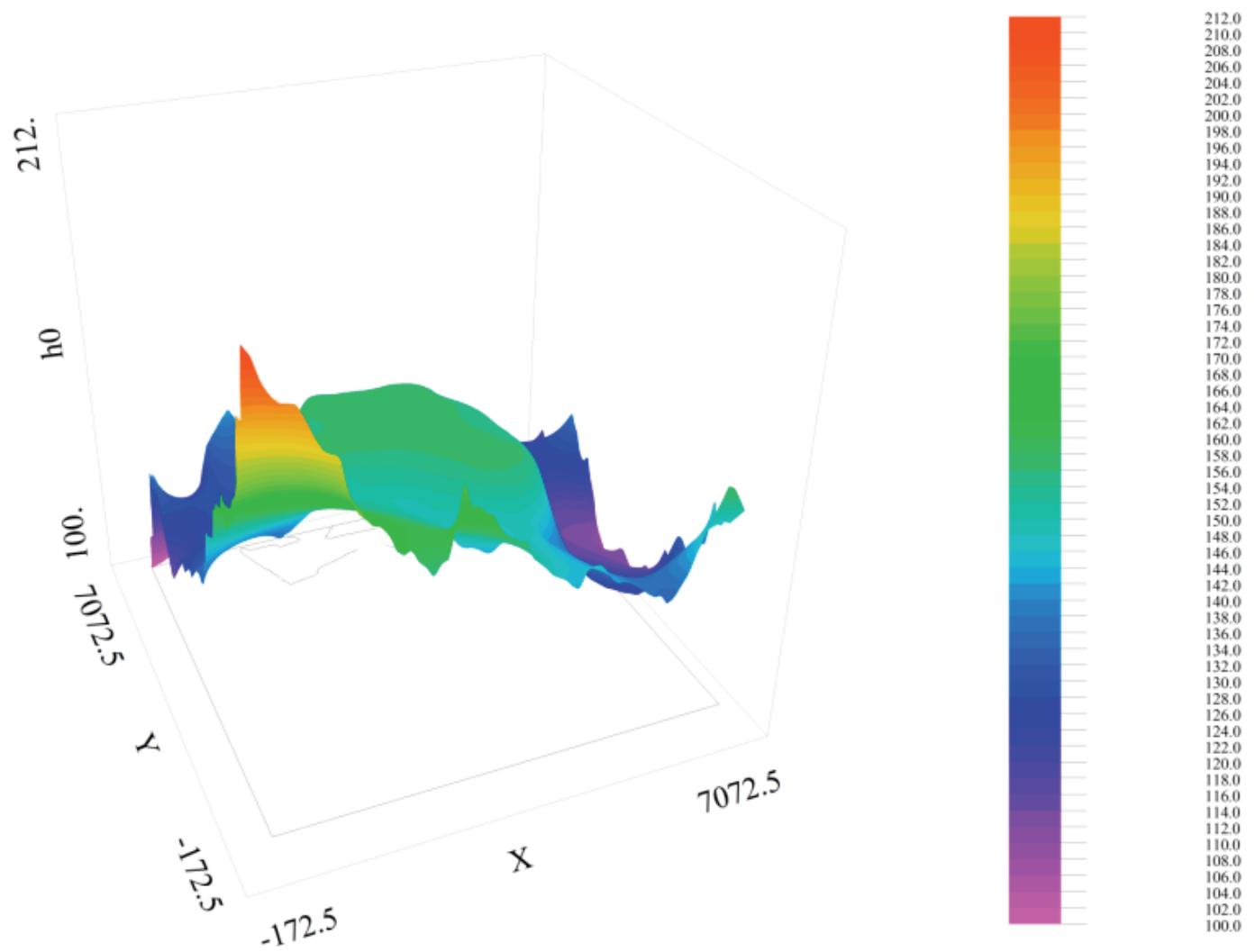

Fig. 13. Height of subterranean water table in three-dimensional space

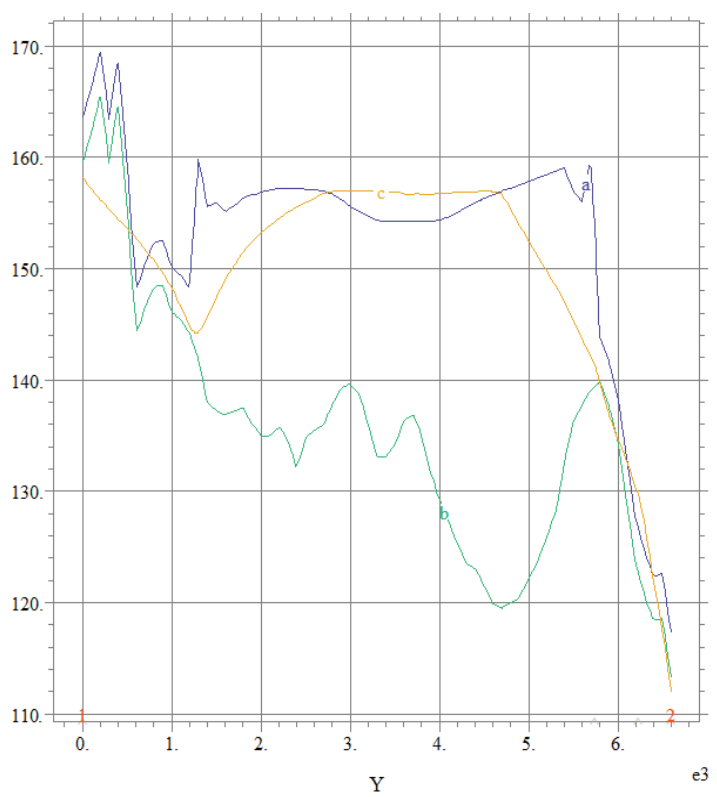

Fig. 14. Location of subterranean water table (c) relative to lake surface (a) and to terrain surface (b) in cross section $y=3500$

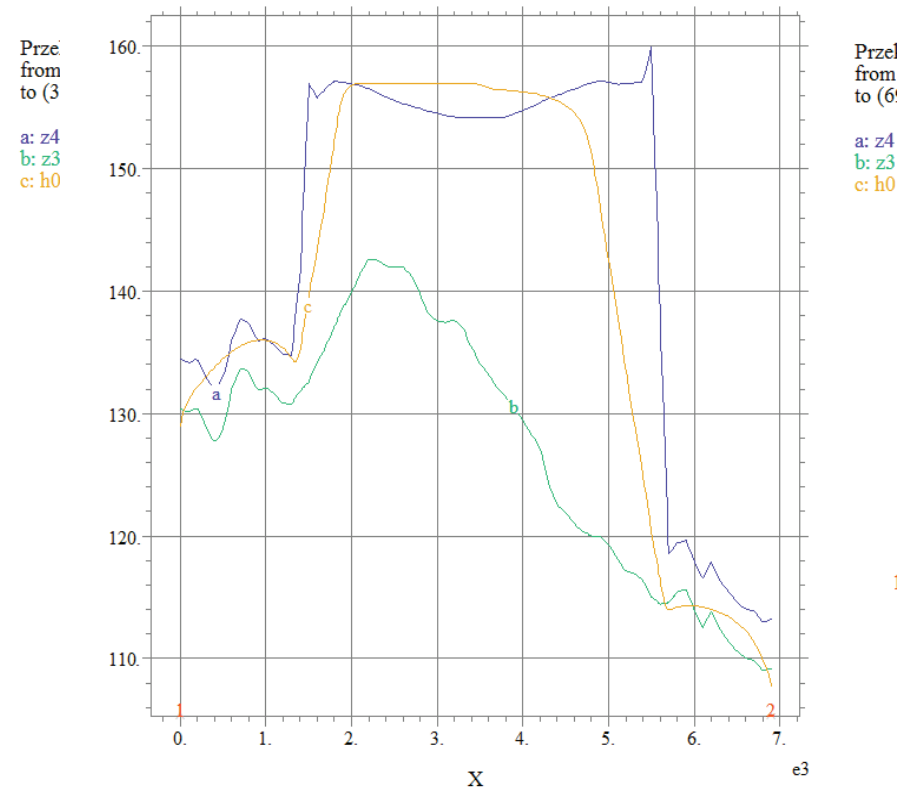

Fig. 15. Location of subterranean water table (c) relative to lake surface (a) and to terrain surface (b) in cross section $x=3500$ 


\subsection{QUALITATIVE ANALYSIS AND SUMMARY OF RESULTS}

The computational results, in the form of a text file containing the coordinates of the nodal points of the mesh generated from the free surface of the subterranean waters, were compared with the real measurements obtained from the piezometers installed on the lake and in the surrounding terrain. The coordinates of the points, contained in the text file, were used to generate the surface of the subterranean water table in the InRoads software. The shape of the surface was rendered by means of isolines in Figs. 16 and 17.

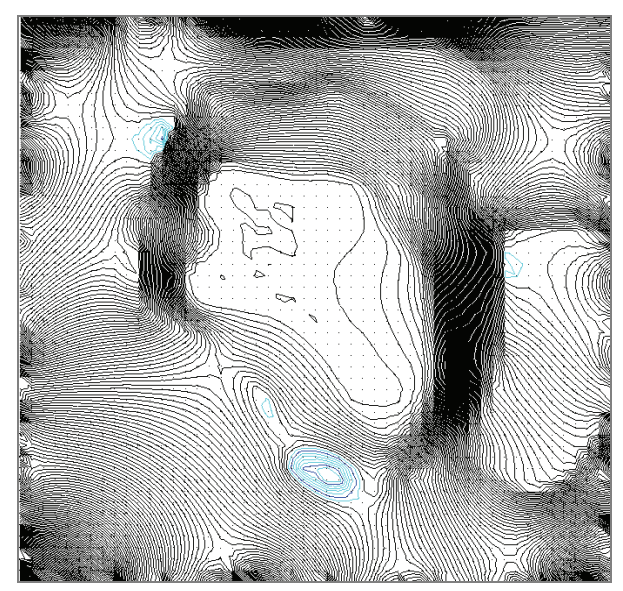

Fig. 16. Subterranean water table surface in the form of isolines

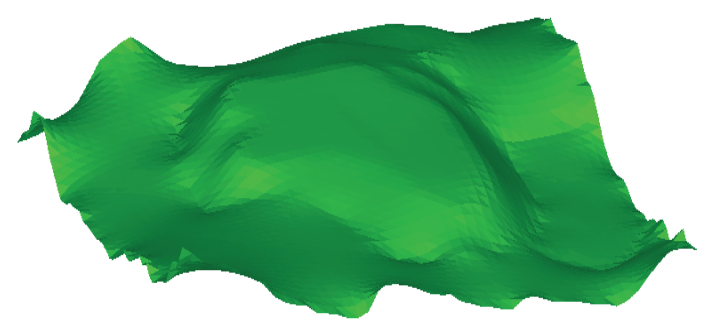

Fig. 17. Surface of subterranean water table

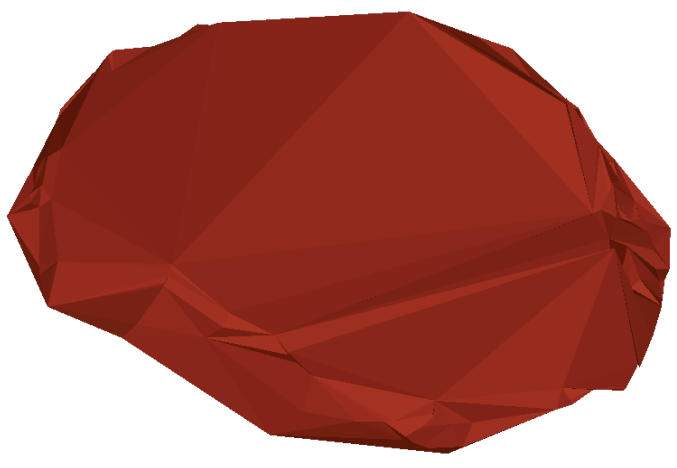

Fig. 18. Interpolated surface generated from piezometric measurements
For comparison purposes, the surface of the water was generated (similarly as above) from the results of the piezometric measurements performed on the lake's dam and in the neighbouring terrain. The visualization of this surface is shown in Fig. 18. All the displayed surfaces have been magnified twenty times relative to the $z$-axis to facilitate analysis.

The shapes of the two surfaces are similar, which shows that the numerical filtration flow model performs properly. The considerable irregularity of the other surface is a side effect of the poor condition of the measuring apparatus. It should be noted that the piezometric measurements do not supply information about the position of the water table within the waste massif, but only along its periphery, whereby there are a few flat fragments covering about $90 \%$ of the surface. Consequently, the measurement results have only a general character. Whereas the surface obtained from the model computations much more precisely renders the position of the water table within the waste massif. Owing to its high accuracy the surface can be used in more comprehensive analyses without any risk of compounding errors and discontinuities. In order to more accurately identify the positions of the two surfaces, the surface of the terrain and the lake and the subterranean water surface obtained from the numerical model computations have been put together in Fig. 19. One can see there the place where the free surface of the water table extending above the surface of the lake forms a basin whose shape is similar to the one present in the natural conditions, which proves that the obtained results are correct.

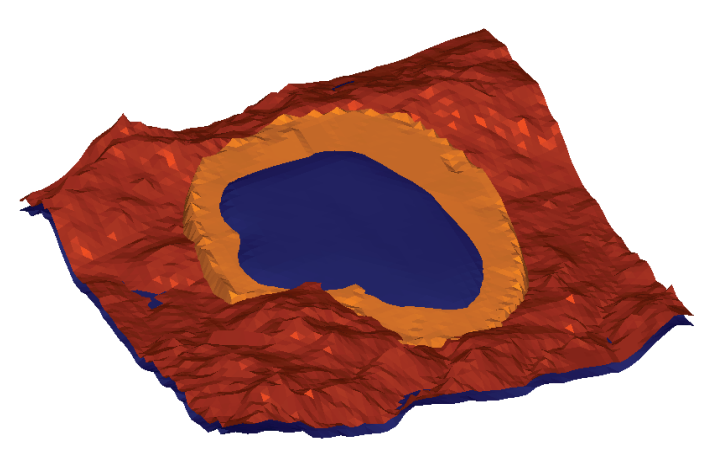

Fig. 19. Terrain and lake surface put together with subterranean water surface obtained from numerical model computations

Finally, the validity of the results was ascertained through cross sections in which the outlines of the lake surface, the terrain surface and the subterranean water surface, obtained from respectively measurements and computations are shown. The results in the form of 8 cross sections along a straight line parallel 

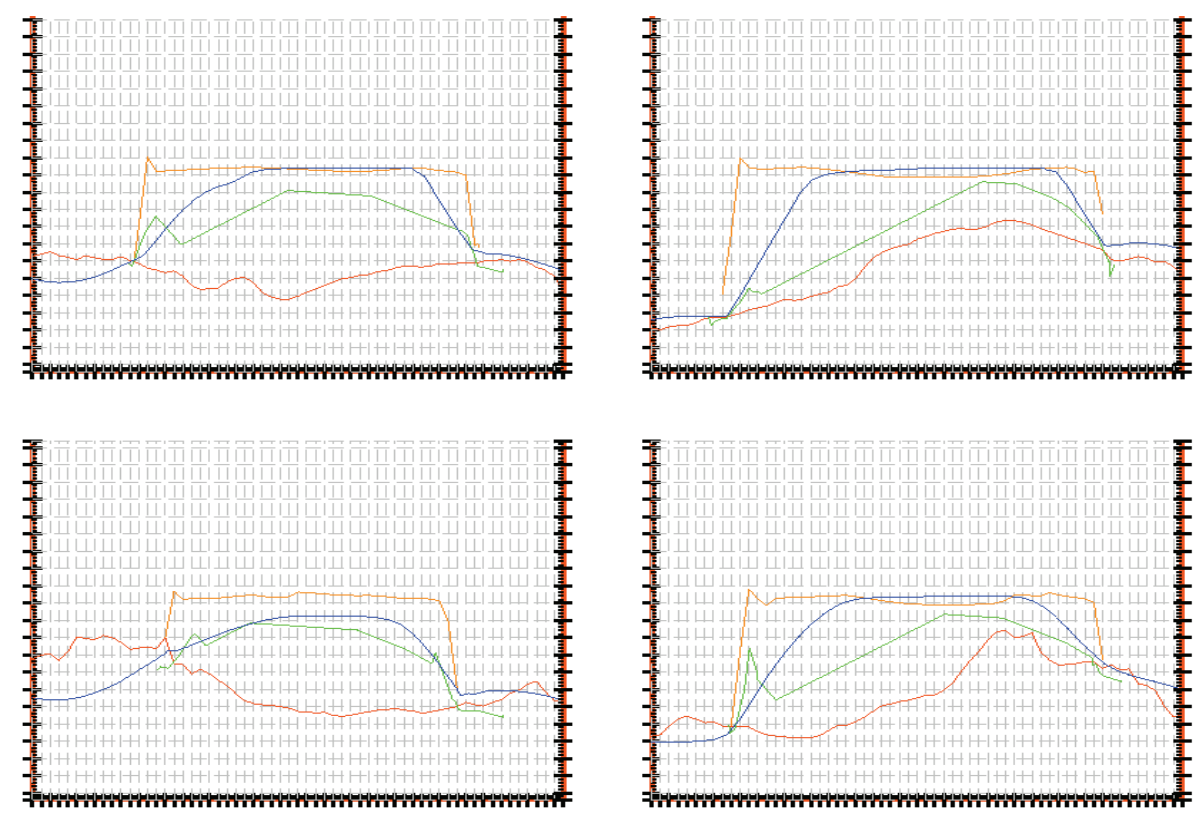

Fig. 20. Comparison of water surface position obtained from respectively computations and piezometric measurements in $y$-z plane, throughout the whole $x$ range, part 1
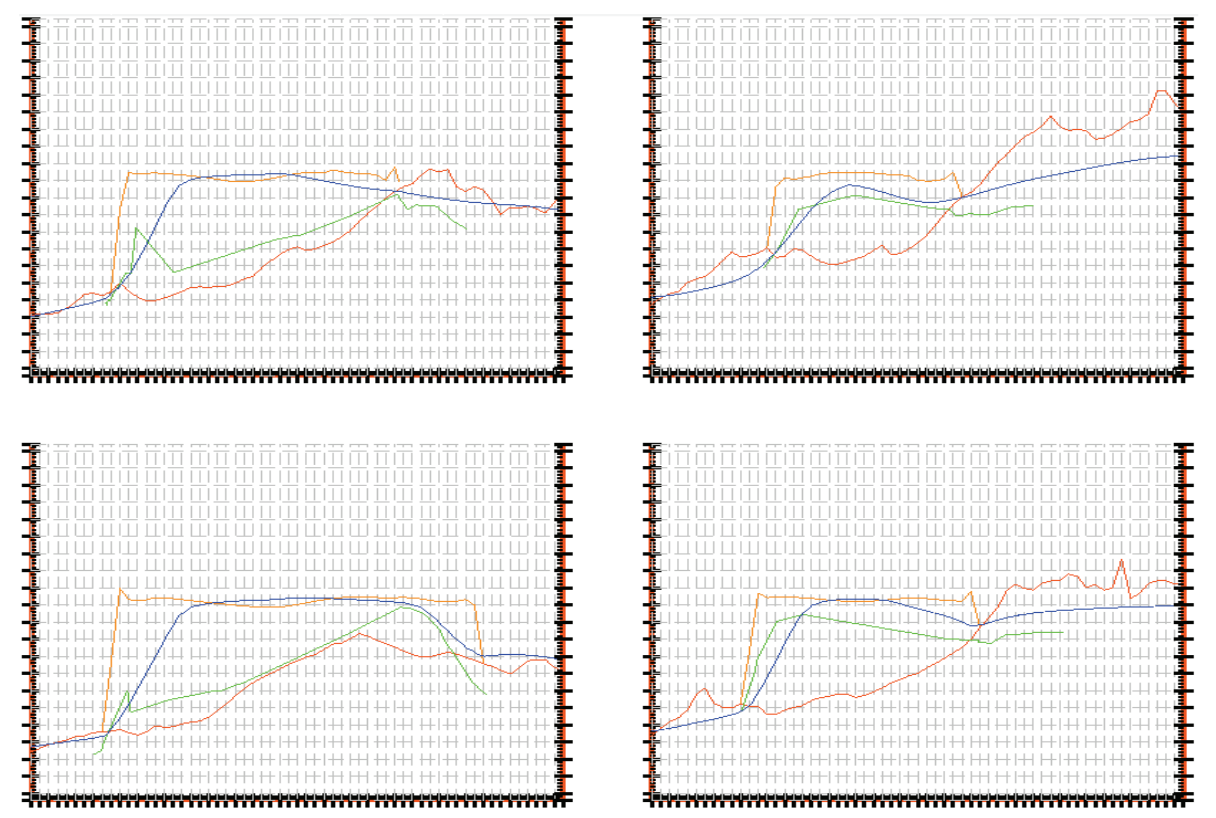

Fig. 21. Comparison of water surface position obtained from respectively computations and piezometric measurements, in $y$-z plane, throughout the whole $x$ range, part 2

to the $y$-axis are shown in Figs. 20 and 21. The computed water surface is marked with blue and the measured one with green. One can see similarity in the water surface outline near the lake slopes while in some of the cross sections distinct differences are visible in the central part of the lake. This is due to the lack of measurements from this area and to the linearly interpolated surface. Another possible cause of the differences can be the way of formulating bound- ary conditions in the model. It is possible that water occurs on two levels. In such a case, the body of water in the lake has no contact with the underground water table since it is separated from the latter by a layer of poorly permeable soils through which water slowly infiltrates to the free surface of the subterranean water situated below. The above case should be examined after the water infiltration possibility has been thoroughly investigated. 
The developed 3D numerical model of the filtration flow of water in the area of the Żelazny Most flotation tailings disposal lake differs from the models of this lake reported in the literature: Strzelecki and Bartlewska [6], Nowak et al. [4], [5], in the fact that it incorporates the real system of subsoil strata under the lake and in the surrounding area. The numerical model is fully three-dimensional. Previously, either a 2D model with the solution of the Boussinesq equations (Nowak, Strzelecki M., Strzelecki T. [5]) or a 3D model with a geometrical model without the subsoil strata (Strzelecki and Bartlewska-Urban [6]), had been used. The lake's drainage, in the form of the drainage ditch and the draining systems within the lake area, was taken into account in the numerical computations. The computation results were compared with the results of piezometric measurements acquired from flotation tailings disposal lake drainage monitoring. The comparison showed good agreement between the respective sets of results. The presented numerical model of the lake can be the starting point for more comprehensive analyses of the state of stress and strain, the displacements of the lake surface and indicated hazards.

\section{REFERENCES}

[1] Czmiel J., Markiewicz A., The distribution of pressures in the deposits and in the dam bodies and their subsoil, An analysis of the changes in piezometric pressures in the period from the beginning of the disposal lake to the end of 1997 (Stage 3), CBPM "Cuprum", Wrocław, 1998, (in Polish).

[2] DYOR S., Wykształcenie i stratygrafia utworów trzeciorzędowych na obszarze Legnicko-Glogowskiego Okręgu Miedziowego, [in:] Przew. 40 Zjazdu PTG, Zielona Góra 1978, 210-214.

[3] FlexPDE User Guide Version 2.19, PDE Solutions, 2000.

[4] Nowak J., Strzelecki M., Strzelecki T., A numerical model of the filtration flow within the flotation tailings disposal lake, Cuprum, 2008, No. 4, 63-86, (in Polish).

[5] Nowak J., StRzeleCKi T., StRZelecki M., The practical use of the method of identifying geotechnical hazards to a large-size hydrotechnical structure on the basis of computations using a spatial model of the water table, Proceedings of the International Congress of Copper Ore Mining: prospects and challenges, Lubin, 24-26 September 2009, Vol. 2, 56-65, (in Polish).

[6] Strzelecki T., BartlewsKa-Urban M., Numerical calculations of the consolidation of flotation waste landfill "Żelazny Most" based on Biot's model with the Kelvin-Voight rheological skeleton, Archives of Civil Engineering, 2011, Vol. 57, No. 2, 199-213.

[7] Strzelecki T., Kostecki S., ŻAK S., The modelling of flows through porous media, Dolnośląskie Wydawnictwo Edukacyjne, Wrocław 2008, (in Polish). 